Research Article

\title{
Establishment and Application of the Void Closure Prediction Model of 316LN
}

\author{
Min Qin, Jiansheng Liu $(\mathbb{D}$, and Jingdan Li \\ College of Materials Science and Engineering, Taiyuan University of Science and Technology, Taiyuan 030024, Shanxi, China \\ Correspondence should be addressed to Jiansheng Liu; jiansliu@163.com
}

Received 22 January 2020; Accepted 11 March 2020; Published 8 May 2020

Academic Editor: Jose Cesar de Sa

Copyright (c) 2020 Min Qin et al. This is an open access article distributed under the Creative Commons Attribution License, which permits unrestricted use, distribution, and reproduction in any medium, provided the original work is properly cited.

\begin{abstract}
The presence of voids in the ingot affects the mechanical properties of the final products of the forging process. It is essential to establish a void closure model to predict cavity closure in the forging process to optimize the forging process and improve forging quality. The main purpose of this study is to obtain an accurate prediction model of void closure for 316LN stainless steel. Using the FEM simulation method to study the closure of spherical voids during forging compression of $316 \mathrm{LN}$ materials, we can accurately characterize the state of void closure. The void closure ratio $K$ under different deformations at $1,200^{\circ} \mathrm{C}$ was counted, and the relationship between $K$ and the effective strain was established to obtain the void closure prediction model of 316LN stainless steel. The void closure prediction model is implanted into DEFORM software through the secondary development method to generate the void closure ratio $K$. In the postprocessing module of DEFORM software, the void closure status of each part during the forming process can be directly observed. Comparing the results of large-scale upsetting experiments and simulation results, the closure error of each part was only $3 \%$, which indicates that the void closure model established in this paper has higher accuracy, which is helpful for the optimization of the forging process and the control of forging quality.
\end{abstract}

\section{Introduction}

As the key parts for heavy machinery and equipment, large forgings are widely used in the fields of nuclear power plants, metallurgy, shipbuilding, aerospace, and the national defense industry. However, void defects, such as shrinkage cavities and porosities, inevitably exist in large ingots due to the nonuniform solidification of the materials during casting. The presence of voids destroys the strength and continuity of the products, causes the concentration of stress and the initiation of cracks, and results in the loss of lifespan and/or the outright discarding of large forgings.

Numerous studies have examined and modeled void closure [1-5]. Budiansky et al. [6] introduced expressions for the volumetric strain rate of a spherical void in nonlinear viscous materials for both high and low stress triaxiality states (HST and LST). Harris et al. [7] proposed a fast converging material-specific void closure model during ingot forging. Feng et al. [8] used a 3D void evolution model to investigate the void closure efficiency in cogging processes of large ingots. Park [9] found that a closure criterion of the spherical void is a function of the effective strain and stress triaxiality. Rahul et al. [10] brought out at every stage the load and torque distribution, effective strain, stress triaxiality factor, void volume fraction, and void healing hydrostatic integration parameter in a model which enabled void closure. Park [11] found that the void closure is dependent on the aspect ratio of the cross section of a void but not on the size of the void. The relationship between the effective strain and the aspect ratio was established by which the closure of such a void with any aspect ratio can be predicted in terms of the effective strain in uniaxial forging. Lee [12] suggested that a local effective strain value of 0.6 or greater must be achieved for void closure during forging.

The gradual elimination of voids in the forging process can be divided into two stages. The void closure is the first stage. At this stage, the forging is deformed at high temperatures, and the void gradually diminishes until the upper and lower surfaces of the void contact. The void closure stage is mainly affected by increasing reduction and its associated 
stress $[6,9,10,12-18]$. The surface bonding is the second stage. At this stage, the upper and lower surfaces of the void are in continuous contact until the surface bonding. The surface bonding stage is not only affected by deformation but also by factors such as temperature, time, and material characteristics [19-21]. Each stage requires independent investigation; the main subject of this paper is the void closure stage.

In this paper, the FEM simulation of void closure during the upsetting process of the $316 \mathrm{LN}$ stainless steel was used to find an accurate parameter to characterize the void closure during forging. By carrying out large numbers of simulation experiments, the relationship between the void closure ratio $K$ and the accurate parameter was analyzed, and the void closure prediction model was obtained. The model was implanted into DEFORM software by the method of secondary development. Void closure at any position was observed on the nondestructive model of forging through DEFORM software. Finally, through the comparison of simulations and large-scale upsetting experiment results, the accuracy and practical significance of the void closure prediction model were verified.

\section{FEM Simulation Analysis}

2.1. Establishment of the FEM Element Model. DEFORM3D software was used in the FEM simulation for the upsetting process of the cylinder sample. Forging samples used in the simulation process were $\Phi 400 \mathrm{~mm} \times 600 \mathrm{~mm}$ cylinders, and the material was 316LN stainless steel. The shape of the void was spherical, and the diameter was $\Phi 20 \mathrm{~mm}$. Due to the symmetry of the cylinder and the symmetry of the upsetting process, this study set 25 voids in the upper left quarter of the cross section of the cylinder. The specific location distribution is shown in Figure 1. In order to avoid the influence between the voids, each of the voids was simulated separately.

In order to facilitate the analysis of the void closure in different positions, the voids were numbered P11-P55 according to their positions, as shown in Figure 1. The hot forging temperature was set as $1,200^{\circ} \mathrm{C}$; the die reduction speed was $4 \mathrm{~mm} / \mathrm{s}$; and the heat transfer coefficient was $3 \mathrm{~W} /$ $\mathrm{m} 2 /$ deg.

In order to better describe the state of void closure, the parameter $\mathrm{Hz}$ was set as the height of the void, that is, the length of the projection of the void on the $Z$-axis during the void closing process, as shown in Figure 2.

2.2. Simulation of Void Closure. The factors that are often used to describe and characterize void closure during forging forming are effective strain $\bar{\varepsilon}[7,8,10-16]$, hydrostatic stress $\sigma_{m}[8,11-14]$, and stress triaxiality $[13-18,22-25]$.

DEFORM uses a value common to metal forming analysis known as the effective or von Mises strain [26]:

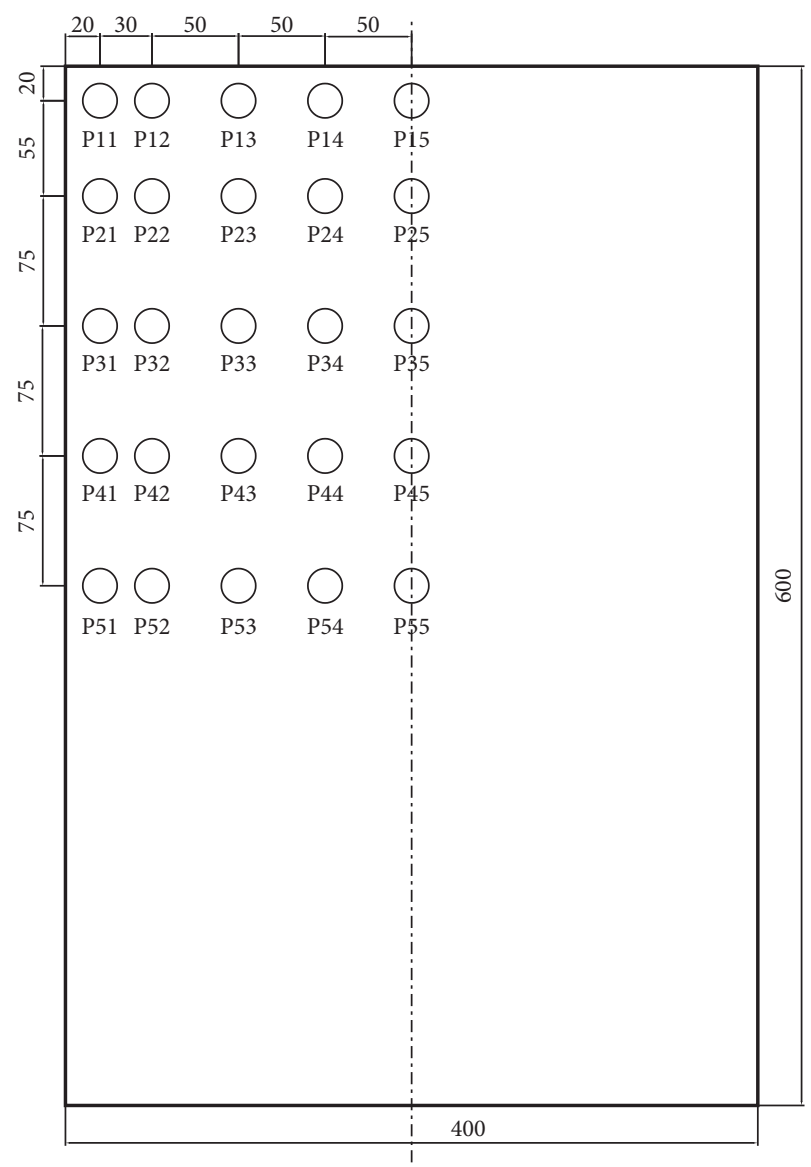

FIgURE 1: Distribution of the void position in the forging blank.

$$
\bar{\varepsilon}=\frac{\sqrt{2}}{3} \sqrt{\left(\varepsilon_{1}-\varepsilon_{2}\right)^{2}+\left(\varepsilon_{2}-\varepsilon_{1}\right)^{2}+\left(\varepsilon_{3}-\varepsilon_{1}\right)^{2}}
$$

where $\varepsilon_{1}, \varepsilon_{2}$, and $\varepsilon_{3}$ are principal strains and $\bar{\varepsilon}$ is the effective strain.

Hydrostatic stress $\sigma_{m}$ is the mean stress:

$$
\sigma_{m}=\frac{1}{3}\left(\sigma_{1}+\sigma_{2}+\sigma_{3}\right)
$$

and $\sigma_{m} / \bar{\sigma}$ is the measure of stress triaxiality, where $\sigma_{m}$ is the hydrostatic stress and $\bar{\sigma}$ is the effective stress.

In order to describe the void closure and analyze the relationship between the void closure and effective strain, hydrostatic stress, stress triaxiality, and other factors, this paper introduces the void closure ratio $K$ as a parameter for description and analysis:

$$
K=\frac{D-H_{z}}{D} \times 100 \%,
$$

where $H_{z}$ is the height of the void, $D$ is the original diameter of the void before deformation, and $K$ is the void closure ratio. 


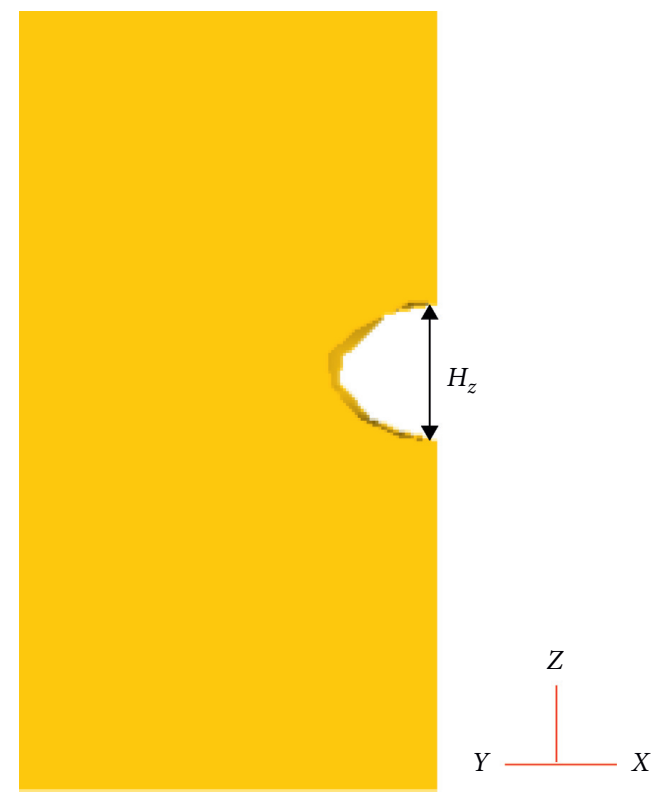

FIgURe 2: Void closure height $H_{\mathrm{z}}$.

During the cylinder upsetting process, the void was under compressive stress, and the values of hydrostatic stress and stress triaxiality are negative. In order to analyze the relationship between void closure ratio and these factors, the absolute values of hydrostatic stress and stress triaxiality were used in the analysis. Figure 3(a) represents the conditions for P15, which was at the end of the cylinder. During the upsetting process, the absolute values of the hydrostatic stress and the triaxiality of the stress showed the same upward trend as the void closure ratio, though the values were offset such that the curves did not show a good fit. However, the effective strain curve showed the same positive trend with better curve fitting.

Figure 3(b) represents the conditions for P51, near the surface edge of the cylinder. The absolute values of the hydrostatic stress and the triaxiality of the stress showed an upward trend when the amount of deformation was less than $35 \%$ and a downward trend when the amount of deformation was greater than 35\%, which was inconsistent with the trend shown by void closure ratio, while effective strain was close to the trend of the void closure ratio, and the curve fit was better.

Figures 3(c) and 3(d) represent P55 which is at the center of the cylinder. The absolute values of voids, hydrostatic stress, and stress triaxiality as well as the changes to effective strain and the closing ratio $e$ of the void were the same, but the curve of effective strain was closer to the curve of the void closure ratio.

During the process of cylinder upsetting, the void closure ratios at different positions at the same time did not match the trends for the absolute values of hydrostatic stress and stress triaxiality. As shown in Figure 4, the void closure ratio from P22 to P25 showed a downward trend, while the absolute values of hydrostatic stress and stress triaxiality showed an upward trend. The effective strain is thus the best value to reflect the trend of void closure.
In summary, in the process of cylindrical upsetting, effective strain can not only reflect the void closure state of the same void at different times but also the void closure state of different voids at the same time. Therefore, effective strain was used to describe the void closure state.

\section{Establishment of the Prediction Model of Void Closure}

In order to establish an accurate relationship between the void closure state and effective strain during the forging process, related experiments were designed. The experimental object was processed into a cylinder with a diameter of $\Phi 100 \mathrm{~mm}$ and a height of $140 \mathrm{~mm}$ and punched cylindrical through-holes with a diameter of $\Phi 5 \mathrm{~mm}$ at different positions of the cylinder, as shown in Figure 5(a). The forging was heated at a rate of $15^{\circ} \mathrm{C} / \mathrm{s}$ and maintained for $2 \mathrm{~h}$ after heating to $1,200^{\circ} \mathrm{C}$ to ensure uniform temperature. The forgings were upset on a $5 \mathrm{MN}$ press with deformations of $15 \%$ and $36.5 \%$, respectively, and quenched after the deformation was completed. Figure 5(b) shows the deformation and shape of the cylindrical through-hole when the deformation was $36.5 \%$.

When the deformations were measured at $15 \%$ and $36.5 \%$, the void height at the positions of the a, b, and $c$ through-holes was also measured. Using DEFORM analysis, effective strain at the corresponding positions of the $a, b$, and $c$ axis of the holes was obtained.

Figure 6 represents the relationship between the experimentally obtained void closure ratio $K$ and effective strain obtained by the finite element simulation. The data distribution conforms to the power exponential equation. Therefore, formula (3) was used to describe this relationship. By fitting data, the parameter A was calculated as 1.15 , and $n$ was calculated as $1 / 2$. The void closure prediction model is shown in the following formula:

$$
\begin{aligned}
& K=A \bar{\varepsilon}^{n}, \\
& K=1.15 \bar{\varepsilon}^{1 / 2} .
\end{aligned}
$$

$K$ is the void closure ratio; $\bar{\varepsilon}$ is the effective strain. Void closure ratio $K \in 0,1$; when $1.15 \bar{\varepsilon}^{1 / 2}$ is greater than 1 , makes $K=1$.

Observation experiment results show that when the void closure ratio reached more than $98 \%$, that is, when the distance between the upper and lower surfaces of the cavity observed under the microscope was less than $120 \mu \mathrm{m}$, the upper and lower interfaces of the void were completely in contact. At this time, the void can be considered closed, as shown in Figure 7.

\section{Secondary Development and Application of the Void Closure Prediction Model}

DEFORM software is commonly used finite element calculation software. Its own simulation function is powerful, and it has the function of secondary development $[8,11-15]$. In this study, the previously obtained void closure prediction 


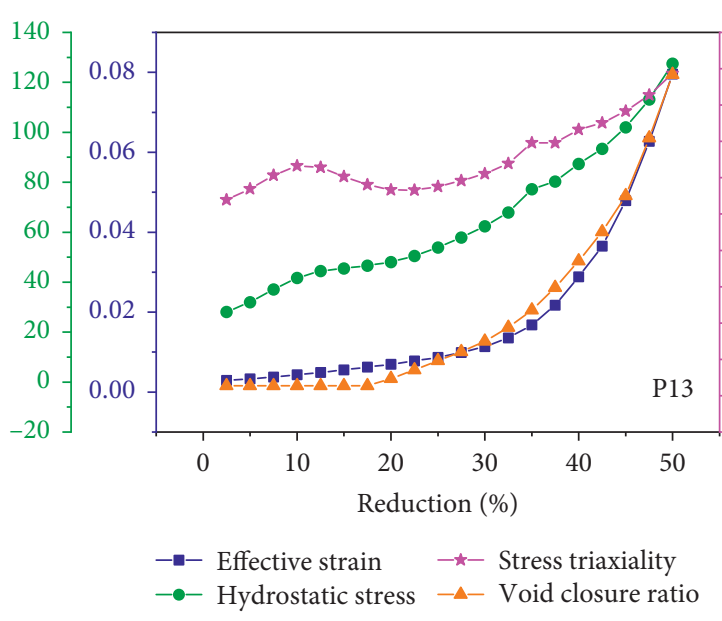

(a)

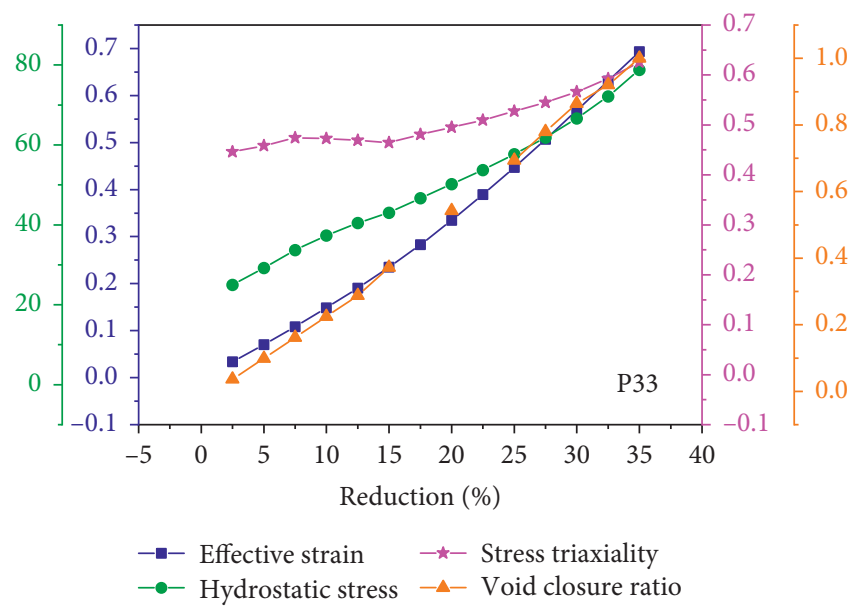

(c)

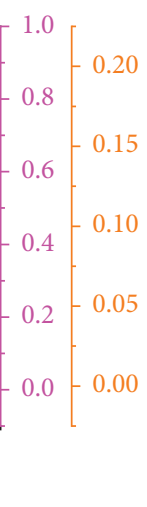

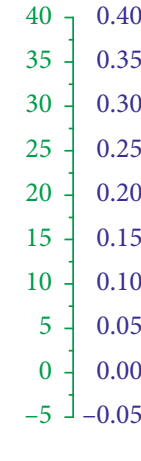

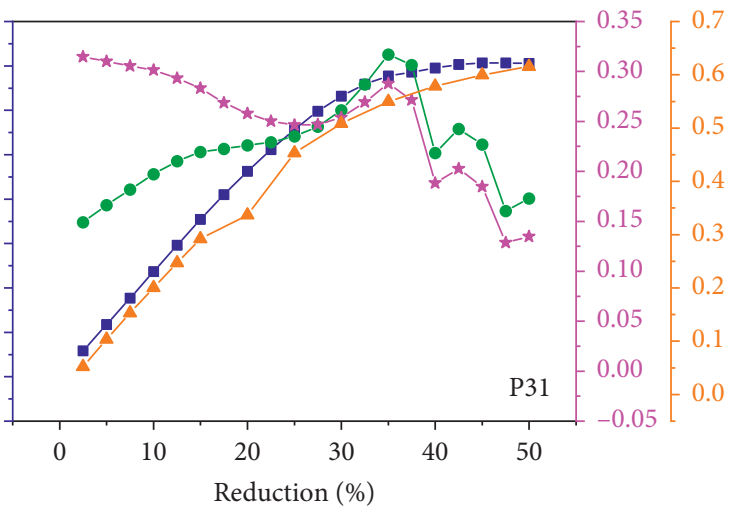

$\begin{array}{ll}-- \text { Effective strain } \quad-\star-\text { Stress triaxiality } \\ -- \text { Hydrostatic stress } & -\Delta-\text { Void closure ratio }\end{array}$

(b)

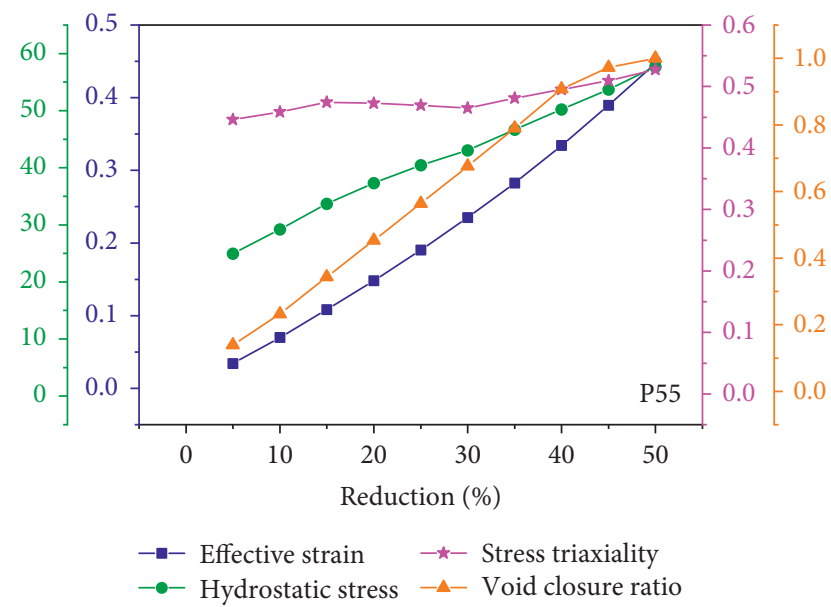

(d)

Figure 3: Relationship between void closure ratio and effective strain, absolute value of hydrostatic stress, and stress triaxiality. (a) P13. (b) P31. (c) P33. (d) P55.

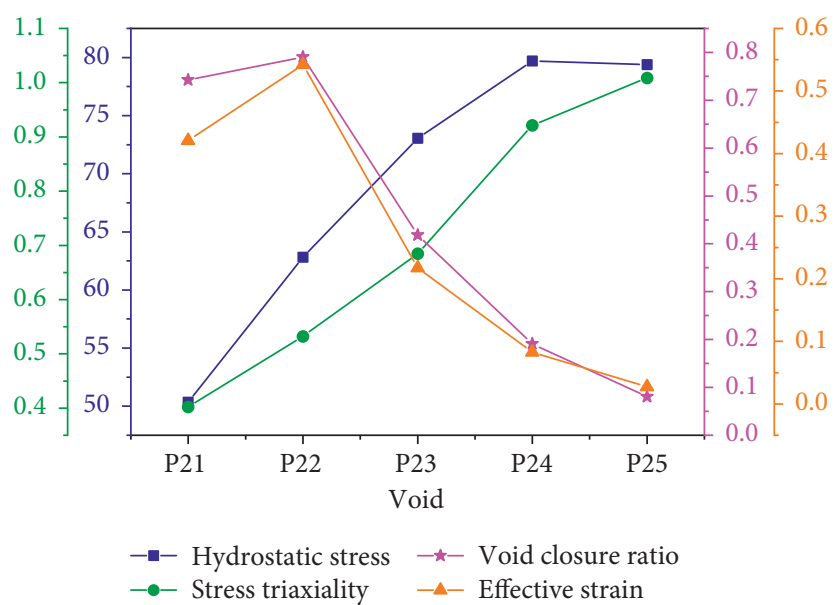

FIGURE 4: Relationship between void closure ratio of P21-P25 voids and effective strain, absolute value of hydrostatic stress, and stress triaxiality at $30 \%$ deformation. 


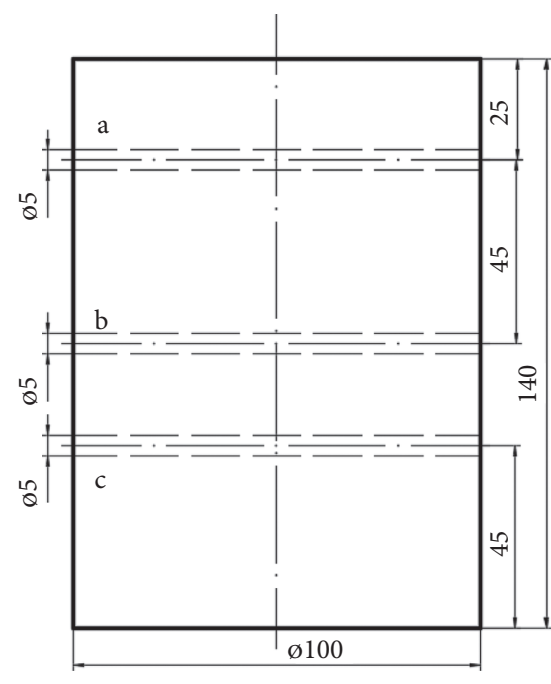

(a)

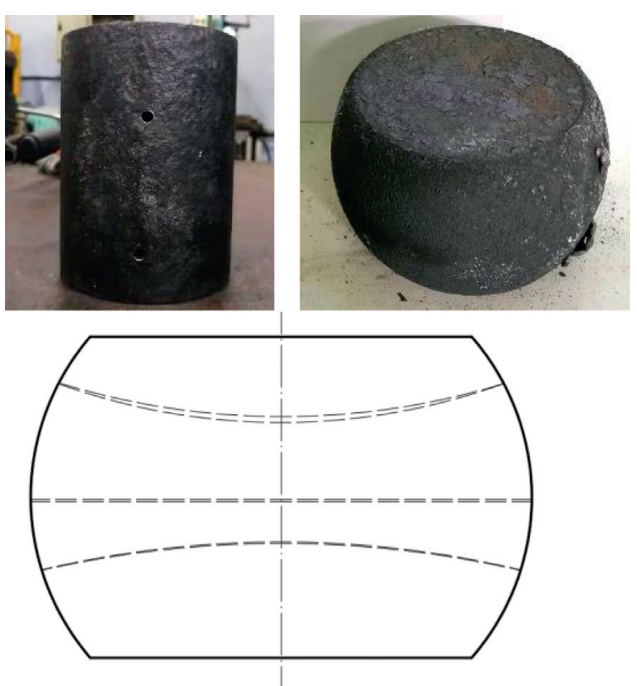

(b)

FIGURE 5: (a) Schematic diagram of through-hole location. (b) Deformation and shape of the cylindrical through-hole when the deformation is $36.5 \%$.

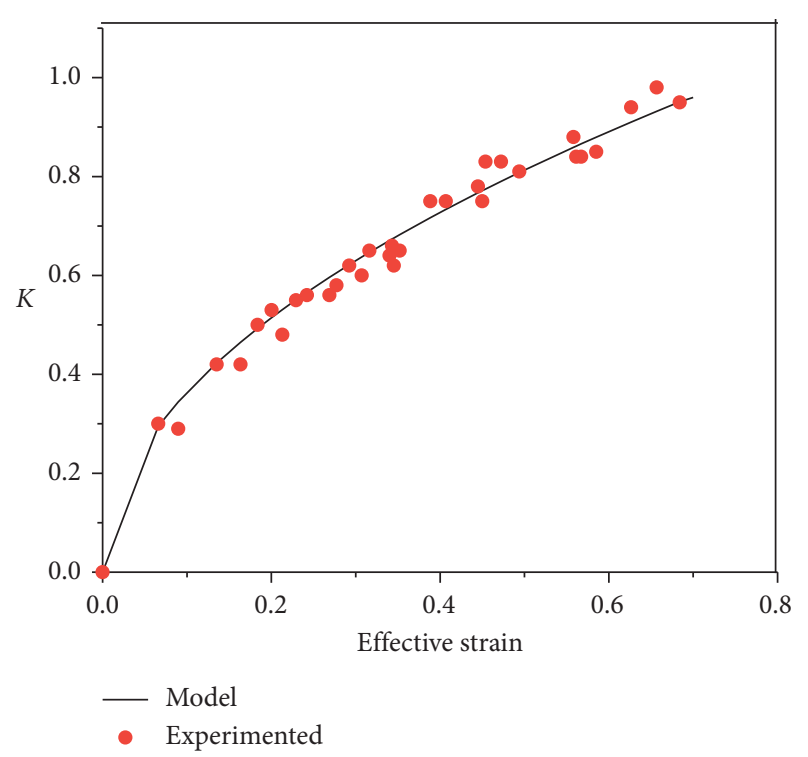

Figure 6: Relationship between actual void closure ratio and effective strain.

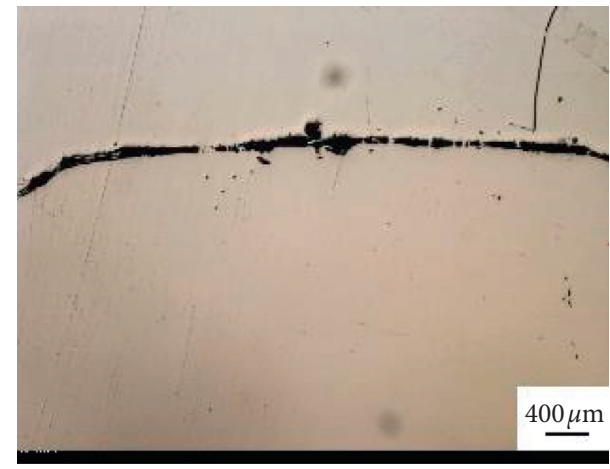

FIgURE 7: The void was closed. model was implanted into DEFORM software through a secondary development method. Through use of the user parameter $K$, which can be found in the DEFORM software postprocessing module, void closure can be determined for any location at any time.

In open forging of large forgings, columnar crystals are often broken by first upsetting with large deformation, and problems such as void and porosity are solved [11, 21, 22]. DEFORM software was used to simulate this $\Phi 200 \mathrm{~mm} \times 260 \mathrm{~mm}$ cylinder upsetting process. The user parameter $K$ can be used to observe the void closure of each part of the cylinder. Figure 8 shows the closing of the void in each part of the cylinder when the cylinder deformation is $40 \%$. $K$ is equal to 1 at the center of the cylinder, which indicates that the void in this position has been closed. $K$ is $0.1 \sim 0.7$ at the end and surfaces of the cylinder, showing that the void at the edge is not well closed. This is mainly because the end surface of the cylinder is in contact with the mold, which is a difficult-to-deform area, and the metal has poor fluidity, making voids in this area difficult to close, which is in line with the actual deformation. In order to verify the accuracy of the model, a sample of $\Phi 200 \mathrm{~mm} \times 260 \mathrm{~mm}$ was processed with 316LN material, and a hole of $\Phi 5 \mathrm{~mm}$ was punched at a distance of $55 \mathrm{~mm}$ from the end face, with another hole punched at the center of the sample. The forging temperature was $1,200^{\circ} \mathrm{C}$, and the deformation was $40 \%$. Figures $8(a)-8(d)$ show the morphological characteristics of the void after cutting the cylinder corresponding to points P1, P2, P3, and P4 in Figure 8(e).

Figure 9(a) shows the closing process of the holes at points P1, P2, P3, and P4 obtained by FEM simulation during the entire upsetting process. The closure of P3 is better than that of $\mathrm{P} 2$, and the closure of $\mathrm{P} 2$ is better than $\mathrm{P} 1$. Point P1 is closed when the amount of deformation is $60 \%$, point P2 is closed when the amount of deformation is $50 \%$, point P3 is closed when the amount of deformation is $45 \%$, and point $\mathrm{P} 4$ is closed when the amount of deformation is 


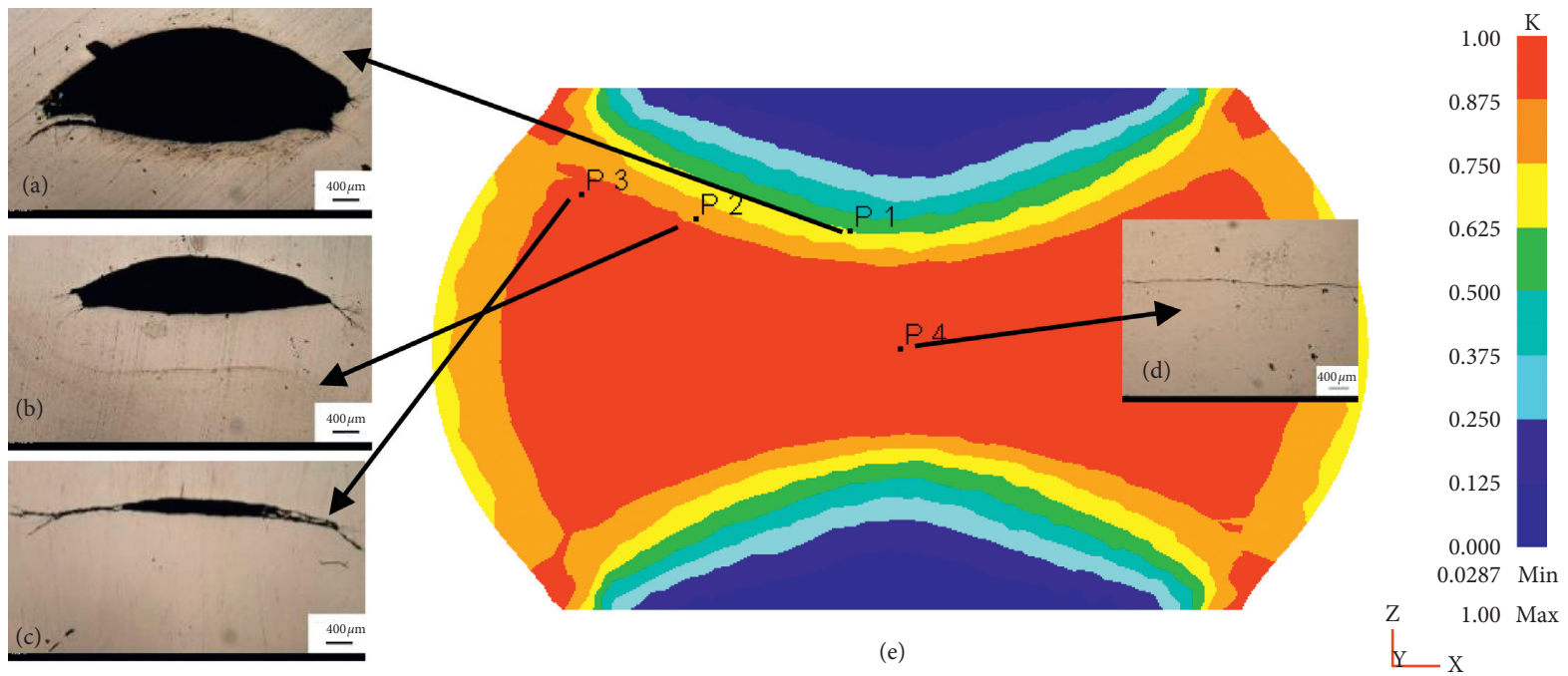

Figure 8: When the deformation of the $\Phi 60 \mathrm{~mm} \times 80 \mathrm{~mm}$ cylinder is $40 \%$, (a) P1, (b) P2, (c) P3, (d) P4 the experimental results, and (e) simulation results of the void closed.

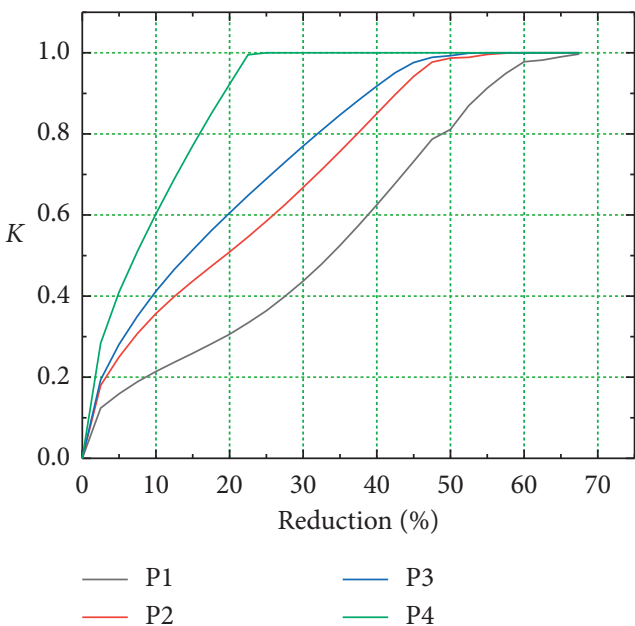

(a)

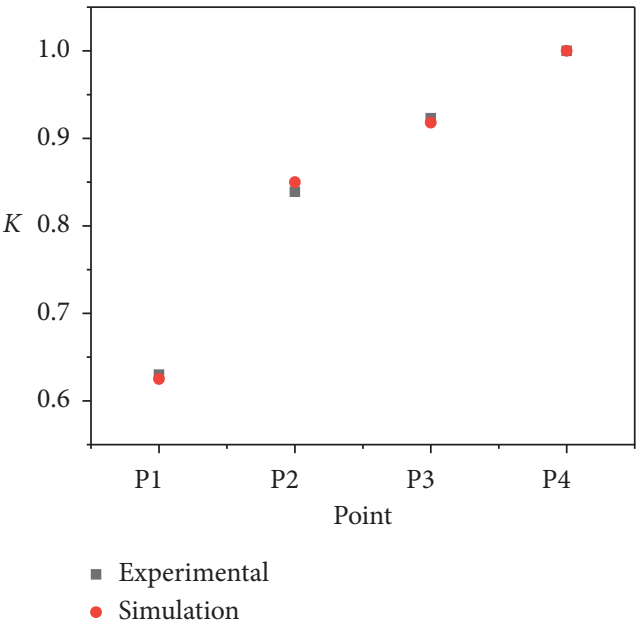

(b)

Figure 9: $\Phi 200 \mathrm{~mm} \times 2600 \mathrm{~mm}$ cylinder. (a) FEM simulation of void closure ratio $K$ at P1, P2, P3, and P4 positions. (b) Experimental and simulation results of void closure ratio $K$ at $\mathrm{P} 1, \mathrm{P} 2, \mathrm{P} 3$, and $\mathrm{P} 4$ positions when the deformation is $40 \%$.

22.5\%. Figure 9(b) shows the comparison between the void closure prediction model and the experimental data at points $\mathrm{P} 1, \mathrm{P} 2, \mathrm{P} 3$, and $\mathrm{P} 4$. The two sets of values are very close, and the error does not exceed $3 \%$. Therefore, the accuracy of the $316 \mathrm{LN}$ void closure prediction model obtained in this paper is high.

\section{Conclusion}

In this study, the void closure stage was studied via the experiment and FEM simulation. The findings are summarized as follows:

(1) The upsetting simulations were used to study the void closure at different points. By introducing the void closure ratio, the accuracy of characterizing the void closure by the three parameters of hydrostatic stress, stress triaxiality, and effective strain was studied. The results show that, under compressive stress, effective strain accurately reflects the void closure state across different times as well as different points at the same time.

(2) A void closure prediction model for $316 \mathrm{LN}$ stainless steel was established. When the forging is under compressive stress, the model can be used to predict the void closure state of any point in the forging. The model shows a positive correlation between the effective strain value and the void closure ratio.

(3) Our findings demonstrate that, in the process of cylindrical upsetting, the void at the center is closed first, while the void at the edge is not yet closed. An 
appropriate process can be selected to increase the effective strain in the end face of the cylinder to promote void closure in that area.

Investigation into the surface bonding stage will be the focus of the next work. Further study will also hone the predictive capacity of the current void prediction closure model and allow its application to the forming process of complex workpieces. The void closure prediction model and the results of surface bonding research will form a complete void elimination model for 316LN. This model will be used to improve the quality of large forgings, enabling best quality with lower costs.

\section{Data Availability}

Some or all data, models, or code generated or used during the study are available from the corresponding author upon request.

\section{Conflicts of Interest}

The authors declare that they have no conflicts of interest.

\section{Acknowledgments}

The authors gratefully acknowledge the funding support from the National Natural Science Foundation of China (Grant 51775361).

\section{References}

[1] J. M. Duva and J. W. Hutchinson, "Constitutive potentials for dilutely voided nonlinear materials," Mechanics of Materials, vol. 3, no. 1, pp. 41-54, 1984.

[2] X.-x. Zhang and Z.-s. Cui, "Theoretical study of void closure in nonlinear plastic materials," Applied Mathematics and Mechanics, vol. 30, no. 5, pp. 631-642, 2009.

[3] P. M. Dixit, US Modelling of Metal Forming and Machining Processes: By Finite Element and Soft Computing Methods, p. 590, Springer, London, UK, 2008.

[4] X.-X. Zhang, Z.-S. Cui, W. Chen, and Y. Li, "A criterion for void closure in large ingots during hot forging," Journal of Materials Processing Technology, vol. 209, no. 4, pp. 19501959, 2009.

[5] X. J. Zhong and G. W. Stewart, "An analysis of the RayleighRitz method for approximating eigenspaces," Mathematics of Computation, vol. 70, no. 234, p. 10, 2000.

[6] B. Budiansky, J. W. Hutchinson, and S. Slutsky, Void Growth and Collapse in Viscous Solids, p. 32, Pergamon Press, Oxford, UK, 1982.

[7] H. Nathan, S. Davood, and J. Mohammad, "Development of a fast converging material specific void closure model during ingot forging," Journal of Manufacturing Processes, vol. 26, pp. 131-141, 2017.

[8] C. Feng, Z. Cui, M. Liu, X. Shang, D. Sui, and J. Liu, "Investigation on the void closure efficiency in cogging processes of the large ingot by using a 3-D void evolution model," Journal of Materials Processing Technology, vol. 237, pp. 371-385, 2016.

[9] J. J. Park, "Manufacturing Engineering Society International Conference Procedia Manufacturing," Procedia Manufacturing, vol. 15, pp. 1841-1846, 2018.
[10] R. S. Nalawade, P. P. Patil, G. Balachandran, and V. Balasubramanian, "Void closure in a large cross section bars hot rolled from a Low alloy steel ingot casting," Transactions of the Indian Institute of Metals, vol. 69, no. 9, pp. 1711-2172, 2016.

[11] J.-J. Park, "Finite-element analysis of cylindrical-void closure by flat-die forging," ISIJ International, vol. 53, no. 8 , pp. 1420-1426, 2013.

[12] Y. S. Lee, S. U. Lee, C. J. Van Tyne, B. D. Joo, and Y. H. Moon, "Internal void closure during the forging of large cast ingots using a simulation approach," Journal of Materials Processing Technology, vol. 211, no. 6, pp. 1136-1145, 2011.

[13] X. X. Zhang, F. Ma, Ma1 Kai, and Li Xia, "Multi-scale Analysis of void closure for heavy ingot hot forging," Modern Applied Science, vol. 6, no. 10, pp. 15-25, 2012.

[14] J.-J. Park, "Prediction of void closure in steel slabs by finite element analysis," Metals and Materials International, vol. 19, no. 2, pp. 259-265, 2013.

[15] J. Chen, K. Chandrashekhara, C. Mahimkar, S. N. Lekakh, and V. L. Richards, "Study of void closure in hot radial forging process using 3D nonlinear finite element analysis," The International Journal of Advanced Manufacturing Technology, vol. 62, no. 9-12, pp. 1001-1011, 2012.

[16] M. Saby, M. Bernacki, E. Roux, and P.-O. Bouchard, "Threedimensional analysis of real void closure at the meso-scale during hot metal forming processes," Computational Materials Science, vol. 77, pp. 194-201, 2013.

[17] Y. Kim, J. Cho, and W. Bae, "Efficient forging process to improve the closing effect of the inner void on an ultra-large ingot," Journal of Materials Processing Technology, vol. 211, no. 6, pp. 1005-1013, 2011.

[18] S. P. Dudra and Y.-T. Im, "Analysis of void closure in opendie forging," International Journal of Machine Tools and Manufacture, vol. 30, no. 1, pp. 65-75, 1990.

[19] B. Wang, J. Zhang, C. Xiao, W. Song, and S. Wang, "Analysis of the evolution behavior of voids during the hot rolling process of medium plates," Journal of Materials Processing Technology, vol. 221, pp. 121-127, 2015.

[20] A. Wang, P. F. Thomson, and P. D. Hodgson, "A study of pore closure and welding in hot rolling process," Journal of Materials Processing Technology, vol. 60, no. 1-4, pp. 95-102, 1996.

[21] B. Xu, M. Sun, and D. LI, "The void close behavior of large ingots during hot forging," Acta Metallurgica Sinica, vol. 48, no. 10, pp. 1194-1200, 2012.

[22] G. Banaszek and A. Stefanik, "Theoretical and laboratory modelling of the closure of metallurgical defects during forming of a forging," Journal of Materials Processing Technology, vol. 177, no. 1-3, pp. 238-242, 2006.

[23] Y. H. Ji and J. J. Park, "Development of severe plastic deformation by various asymmetric rolling processes," $\mathrm{Ma}$ terials Science and Engineering: A, vol. 499, no. 1-2, pp. 14-17, 2009.

[24] M. Tanaka, S. Ono, and M. Tsuneno, "Numerical analysis on void crushing during side compression of round bar by flat dies," Journal of Japanese Society for Technology of Plasticity, vol. 28, pp. 238-244, 1987.

[25] M. Nakasaki, I. Takasu, and H. Utsunomiya, "Application of hydrostatic integration parameter for free-forging and rolling," Journal of Materials Processing Technology, vol. 177, no. 1-3, pp. 521-524, 2006.

[26] Scientific Forming Technologies Corporation, DEFORM V11.0 (PC) Documentation, pp. 684-686, Scientific Forming Technologies Corporation, Columbus, OH, USA, 2014. 